\title{
Industrial Decomposition of Regional Economic Differences in Beijing, Tianjin and Hebei Metropolitan Area
}

\author{
Songlin Li \\ School of Management, China University of Mining\& Technology (Beijing), Beijing 100083, China. \\ 1152053083@qq.com
}

\begin{abstract}
Using the method of decomposition of Theil index and the Gene coefficient of the industry, according to the GDP data of Beijing Tianjin Hebei metropolitan area of 2005-2015 years of each county unit, discusses the effect on industrial structure, regional difference of county economy unit of the metropolitan dynamic and concentration effect. The results show that:2005-2015 years of metropolitan economic difference between cities in the narrow gap is narrowing, the economic differences between urban and rural areas are mainly concentrated in the industrial area is third; The difference of determinants of overall county economy in Beijing Tianjin Hebei metropolitan area; Industrial structure effect to expand the county economy gap, and the industry concentration effect has eased the role of the county economy gap, especially the concentration effect of the third industry, the key role in reducing regional economic differences in the Beijing Tianjin Hebei metropolitan.
\end{abstract}

Keywords: Metropolitan area, Economic differences, Gini coefficient, Industrial structure.

\section{Introduction}

As the core of the economic circle around Bohai, the regional economic development of Beijing, Tianjin and Hebei is swift and violent. However, at the same time of rapid economic development, a series of economic problems are also slowly showing, among them, the unbalanced development of regional economy and the phenomenon of two element structure are the most serious. Regional economic disparity is an important aspect of economic research, the social problems caused by it are more concerned by governments and managers at all levels. The study of regional economic differences has never stopped. Scholars have studied the regional economic differences in the national level, the large region, the provincial and the municipal levels, and have accumulated a lot of research results [1-4].

Industrial structure is one of the important factors that affect regional economic growth. Many domestic scholars have studied the regional economic disparity from the perspective of industrial structure. With the introduction of a series of policies on regional economic integration of Beijing, Tianjin and Hebei, and the continuous strengthening of the concept of integration of Beijing, Tianjin and Hebei. What is the current situation of regional economic disparity in Beijing Tianjin Hebei metropolitan area? Which industry has the greatest impact on the economic difference of Beijing Tianjin Hebei metropolitan area? How does industrial structure effect and industrial concentration effect affect the economic difference of Beijing Tianjin Hebei metropolitan area? This paper makes a study of these problems to provide a reference for Beijing Tianjin Hebei regional economic integration strategy.

\section{Research Methods}

\subsection{Theil Index.}

Theil index is a commonly used method for quantitative analysis of regional economic disparity. Its advantage is to divide the overall regional economic disparity into inter regional differences and intra-regional differences. It can well reflect the contribution of inter-regional differences and regional differences to the overall economic disparity [5]. Using the Theil index to quantify the economic differences of Beijing Tianjin Hebei metropolitan area, we can clearly and intuitively get the trend of economic difference in Beijing Tianjin Hebei metropolitan area [6]. The calculation formula is as follows: 


$$
\begin{gathered}
T=T_{B R}+T_{W R} \\
T_{B R}=\sum_{i=1}^{n} \frac{Y_{i}}{Y} \log \left(\frac{Y_{i} / Y}{P_{i} / P}\right) \\
T_{W R}=\sum_{i=1}^{n} \frac{Y_{i}}{Y}\left[\sum_{j} \frac{Y_{i j}}{Y} \log \left(\frac{Y_{i j} / Y_{i}}{P_{i j} / P_{i}}\right)\right]
\end{gathered}
$$

\subsection{Gini Coefficient.}

The Gini coefficient is mainly used to measure the uneven distribution of wealth or income. Its value is between $0-1$ and the equivalent value is 0 , indicating that the allocation is completely average and the equivalent value is 1 , indicating the distribution and unbalance. Some scholars have found that the economic differences can be decomposed by industry to get Gini coefficient of various industries, so as to study the impact of different industries on the overall economic disparity. The formula for calculating the Gini coefficient is shown as follows.

$$
\begin{gathered}
G=\sum_{k}^{3} S_{k} G_{k} \\
G_{k}=\left(\frac{2}{n^{2} \times \mu_{k}}\right) \times \sum_{r=1}^{n}\left(r \times y_{r k}\right)-\frac{n+1}{n} \\
\Delta G=\sum_{k} \Delta S_{k} G_{k}+\sum_{k} S_{k} \Delta G_{k}+\sum_{k} \Delta S_{k} \Delta G_{k}
\end{gathered}
$$

\section{The Present Situation of Economic Difference}

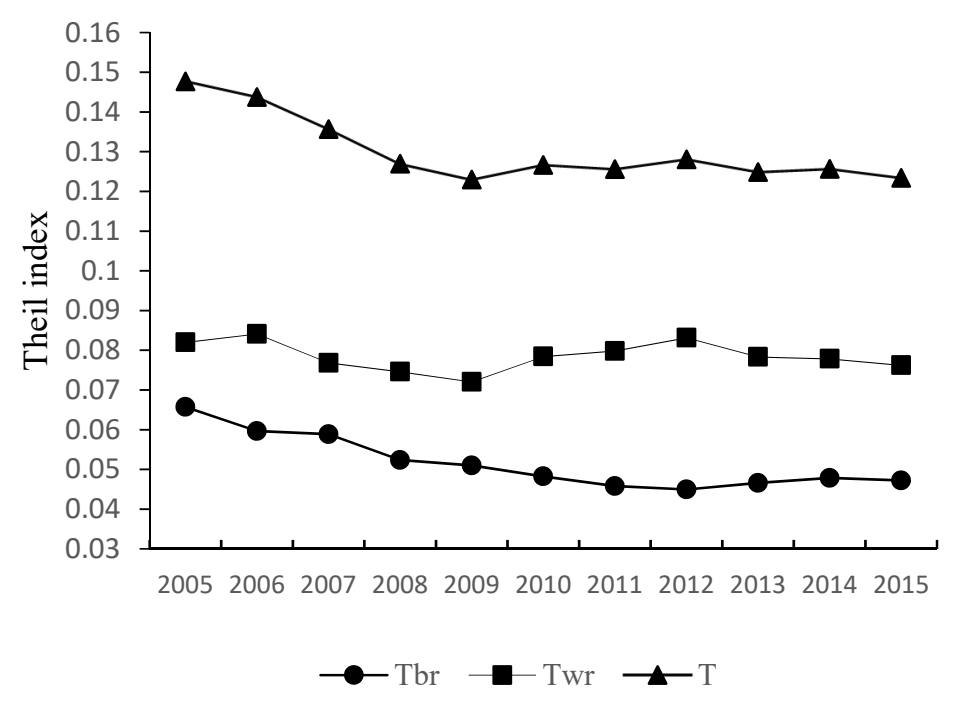

Fig. 1 Theil index of the metropolitan area of Beijing, Tianjin and Hebei

Figure 1 is the calculation result of the Theil index of 146 counties in 10 cities of Beijing Tianjin Hebei metropolitan area. It reflects the evolution trend of economic difference in Beijing Tianjin Hebei metropolitan area in the past 2005-2015 years. The overall regional gap in the metropolitan area of Beijing, Tianjin and Hebei has declined obviously in the past 2005-2009 years. The overall economic differences in the 2010-2015 years have been basically stable, although there are slight fluctuations, but the volatility is small. The evolution of the regional internal gap in the metropolitan area of Beijing, Tianjin and Hebei is divided into three stages. In the 2005-2009 year, the decline 
trend is obvious, but in the 2010-2012 year, the trend of the rebound and the slow decline in the 20132015 years have begun. The interregional gap of Beijing Tianjin Hebei metropolitan area has been decreasing obviously in the past 10 years, and there is a trend of convergence. The gap in the metropolitan area of Beijing, Tianjin and Hebei is larger than the interregional gap, and the gap between the regions is divided by the interregional gap, and the gap between the regions is more than 1.5 times that of the interregional gap. Because the gap is the gap between the districts and counties in the region, the districts represent the urban areas and the counties represent the rural areas, so this is reflected from the other side. The gap between urban and rural areas in Beijing Tianjin Hebei metropolitan area is larger than the regional disparity.

\section{Industrial Decomposition of Economic Differences}

The Gini coefficient of the three industries and contribution degree of Gini coefficient in various industries is calculated as shown in Table 1.It can be seen from the industrial decomposition of Gini coefficient in different years that: The development of the third industry in Beijing Tianjin Hebei metropolitan area is the most uneven, The Gini coefficient of the third industry has been higher than 0.4,but lower than 0.6, but there was a clear downward trend in the 2012-2015 years, it shows that the development of the third industry disequilibrium relieved in recent years. The unbalanced development of the second industry has always been above 0.4 of the warning line, but the situation is not serious. The degree of imbalance in the development of the first industry has increased, but its Gini coefficient is always less than 0.4 , this is due to the decline in the proportion of primary industries in Beijing and Tianjin. The contribution of different industries to the overall economic disparity is not only related to the Gini coefficient of the three industries, but also to the proportion of the industry in the county's national economy.

It can be seen from the contribution of regional differences of three industries to the overall Gini coefficient that the third industry contributes far more than the first, second industry to the economic disparity of the Beijing, Tianjin and Hebei metropolitan area. And there is a tendency to continue to increase. With the sustained growth of the output value of the third industry, its contribution to the overall economic difference increased from $54.77 \%$ in 2005 to $60.54 \%$ in 2015 . The higher value of output share and uneven distribution among counties have caused the regional difference of the third industries, and become the decisive factor of the economic difference in Beijing Tianjin Hebei metropolitan area. The contribution of the first and second industries to the difference of county economy has gradually decreased in the past 10 years. Its contribution to the total Gini coefficient decreased from $4.99 \%$ and $40.24 \%$ to $3.82 . \%$ and $37.83 \%$ respectively. Thus, the Beijing Tianjin Hebei metropolitan area has basically completed industrialization. Although the level of industrialization in different regions is not balanced, it is no longer the dominant factor affecting regional economic disparity.

Table. 1 Industrial decomposition of economic difference

\begin{tabular}{ccccccc}
\hline \multirow{2}{*}{ Time } & \multicolumn{3}{c}{ Gini coefficient } & \multicolumn{4}{c}{ Industrial contribution degree $/ \%$} \\
\cline { 2 - 7 } & $\begin{array}{c}\text { Primary } \\
\text { industry }\end{array}$ & $\begin{array}{c}\text { Second } \\
\text { industry }\end{array}$ & $\begin{array}{c}\text { Tertiary } \\
\text { industry }\end{array}$ & $\begin{array}{c}\text { Primary } \\
\text { industry }\end{array}$ & $\begin{array}{c}\text { Second } \\
\text { industry }\end{array}$ & $\begin{array}{c}\text { Primary } \\
\text { industry }\end{array}$ \\
\hline 2005 & 0.3321 & 0.4244 & 0.5104 & 4.99 & 40.24 & 54.77 \\
2006 & 0.3342 & 0.4457 & 0.5434 & 4.36 & 39.27 & 56.37 \\
2007 & 0.3451 & 0.4523 & 0.5416 & 4.15 & 38.96 & 56.89 \\
2008 & 0.3416 & 0.4347 & 0.5362 & 4.09 & 38.47 & 57.44 \\
2009 & 0.3362 & 0.4276 & 0.5283 & 3.77 & 39.91 & 56.31 \\
2010 & 0.3411 & 0.4406 & 0.5407 & 3.38 & 40.42 & 56.19 \\
2011 & 0.3476 & 0.4482 & 0.5380 & 3.76 & 38.94 & 57.30 \\
2012 & 0.3597 & 0.4455 & 0.5491 & 3.82 & 37.83 & 58.35 \\
2013 & 0.3659 & 0.4513 & 0.5371 & 3.92 & 37.82 & 58.25 \\
2014 & 0.3591 & 0.4430 & 0.5362 & 3.73 & 36.24 & 60.03 \\
2015 & 0.3853 & 0.4332 & 0.4906 & 4.35 & 35.11 & 60.54 \\
\hline
\end{tabular}




\section{Summary}

Based on the 2005-2015 year panel data of Beijing Tianjin Hebei metropolitan area, this paper uses the Tel index and Gini coefficient to decompose the economic differences between Beijing, Tianjin and Hebei metropolitan areas. The results of the study show that: 1 . The overall regional gap in the metropolitan area of Beijing, Tianjin and Hebei has declined obviously in the past 2005-2009 years. The overall economic differences in the 2010-2015 years have been basically stable, although there are slight fluctuations, but the volatility is small. The economic differences between cities are gradually narrowing, and economic differences are mainly concentrated between urban and rural areas.2.The industry with the greatest impact on the economic difference of Beijing Tianjin Hebei metropolitan area is the third industry, and the contribution of the third industries to the economic disparity has been increasing.

\section{References}

[1]. Chen Zhao. Regional development difference from the south to the north in east and middle China. Geographical research. Vol 42 (1999), No. 8, p. 79-96.

[2]. Li XiaoJian, Qiao Jiajun, County Level Economic Disparities of China in the 1990s [J]. Acta geographica sinica.Vol 21(2001),No. 56,p. 136-145.

[3]. Li ErLing, Qin ChengLin. A Positive Study of Regional Economic Diversities between the South and the North in China [J]. Geography and Territorial Research. Vol 31(2002), No. 18, p. 76-78.

[4]. Zhou YuCui, Liao RongHua Research on tendency of uneven development Of Regional Economy in Hunan. Economic Geography. Vol 22(2004) No. 24, p. 343-346.

[5]. Zhou XiaoYan, Hao HuiDi, Ye XinYue, et al.A Spatial-Temporalanalysis Of Regional Economic Inequality In Yellow River Valley. Human Geography Vol 11 (2016) No. 5, p. 119-125.

[6]. Dai PingSheng. Calculations and Characters of the Locational Gini Index and Its Application. The Journal of Quantitative \& Technical Economics. Vol 41 (2015) No. 7, p. 149- 160. 